\title{
Deep Brain Stimulation of Thalamic Nuclei for Treatment of Intractable Epilepsy
}

\author{
Nasrin Mehranfard ${ }^{1}$; Seyed Shahabeddin Sadr ${ }^{2, *}$; Gholam Hossein Meftahi ${ }^{3}$; Zahra Bahari \\ ${ }^{4}$; Maedeh Ghasemi ${ }^{5}$; Leila Farsi ${ }^{2,6}$; Zeinab Naghshband ${ }^{2}$ \\ ${ }^{1}$ Department of Physiology, Paramedical Sciences Faculty, Shahid Beheshti University of Medical Sciences, Tehran, IR Iran \\ ${ }_{2}^{2}$ Electrophysiology Research Center, Neuroscience Institute, Tehran University of Medical Sciences, Tehran, IR Iran \\ ${ }^{3}$ Neuroscience Research Center, Baqiyatallah University of Medical Sciences, Tehran, IR Iran \\ ${ }_{5}^{4}$ Department of Neurophysiology, Shahid Beheshti University of Medical Sciences, Tehran, IR Iran \\ ${ }_{5}^{5}$ Department of Neurophysiology, Shahid Beheshti University of Medical Sciences, The \\ ${ }_{\text {Brain and Spinal Cord Injury Research Center, Neuroscience Institute, Tehran University of Medical Sciences, Tehran, IR Iran }}$ \\ ${ }^{*}$ Corresponding author: Seyed Shahabeddin Sadr, Electrophysiology Research Center, Neuroscience Institute, Tehran University of Medical Sciences, Tehran, IR Iran. \\ Tel: +98-2166521520, Fax: +98-2166521520, E-mail: sadr@tums.ac.ir
}

Received: July 24, 2014; Revised: November 14, 2014; Accepted: December 20, 2014

\begin{abstract}
Context: Epilepsy is one of the most common serious neurological disorders. Antiepileptic drugs are effective in most of patients, but one third of them are poorly controlled or their seizures are refractory to drug treatment. Resective surgery is the most common form of surgical treatment for uncontrolled seizures, but it can be associated with profound complications that limit its use. Hence, alternative therapeutic options are required.

Evidence Acquisition: Deep brain stimulation (DBS) is increasingly used for the treatment of neurological and psychiatric diseases in patients who do not respond to conventional treatment. Significant improvement of well-being (i.e. quality of life) has been observed in patients with Parkinson's disease and obsessive compulsive disorder. As a result of these observations, DBS is now performed in small patient groups for the treatment of many disorders including epilepsy. However, despite its broad therapeutic potential, the appropriate targets for DBS are poorly understood and the application of DBS is most often based on case-reports rather than basic research derived from the laboratory. There are studies suggesting that intractable epileptic seizures can be modified or interrupted by electrical stimulation of subcortical structures including thalamic nuclei. In this review article, we focused on DBS in thalamus to highlight the recent developments and address the perspectives of this approach for the treatment of refractory epilepsy.

Results: Anterior and centromedian thalamic nuclei have a potential role in reducing seizure frequency, particularly in patients with partial and generalized tonic clonic seizures, respectively. Stimulus parameters, especially frequency is an essential factor in determination of the effects of stimulation. Moreover, bilateral stimulation of thalamic nuclei in most experimental and clinical studies appeared to be protective against the incidence of seizure.

Conclusions: Electrical stimulation of anterior and centromedian thalamic nuclei represents a new alternative option in the treatment of patients with refractory epilepsy, particularly in those with partial and generalized tonic clonic seizures who are not candidates for surgery or do not respond to surgery. Although most studies suggest that bilateral high frequency stimulation of thalamic nuclei is effective in reducing seizure activity, further studies are required to determine optimal parameters and risk/benefit ratio of thalamic nuclei DBS for the treatment of intractable epilepsy.
\end{abstract}

Keywords: Deep Brain Stimulation; Thalamic Nuclei; Epilepsy

\section{Context}

Epilepsy is one of the most common serious neurological disorders affecting 1\% of general population (1). One third of patients are poorly controlled or their seizures are refractory to antiepileptic drug therapy (2). Resective brain surgery is a promising therapy for these patients; however, more than $40 \%$ of patients are not eligible for the surgical intervention (2). Hence, alternative treatment possibilities are required. The effectiveness of DBS in the treatment of Parkinson's disease has made preparations for the use of this approach in the treatment of intractable epilepsy. DBS is of therapeutic interest for refractory epilepsy, as it reduces seizures in patients with medically refractory epilepsy. Nonetheless, optimal target(s) for DBS application in epilepsy has not been recognized yet.

\section{Evidence Acquisition}

\subsection{What is Deep Brain Stimulation?}

Deep brain stimulation is a surgical treatment in which a device known as brain pacemaker delivers electrical impulses to specific areas in the brain. DBS is an adjustable and reversible approach, which modulates brain func-

Copyright ( 2015, Tehran University of Medical Sciences. This is an open-access article distributed under the terms of the Creative Commons Attribution-NonCommercial 4.0 International License (http://creativecommons.org/licenses/by-nc/4.0/) which permits copy and redistribute the material just in noncommercial usages, provided the original work is properly cited. 
tion, without causing injury to brain tissues. The DBS system is composed of three components: 1- A batteryoperated pulse generator that delivers electrical stimulation to target areas in the brain, 2- An electrode (a thin, insulated wire) which is implanted in a certain brain area, and 3- An insulated wire that connects electrode to pulse generator. After electrode implantation in target site, pulse generator is located under the skin below the clavicle or abdomen. Adverse effects of DBS include depression, apathy, hallucinations, compulsive gambling, cognitive dysfunction and hypersexuality. However, most adverse effects have been reported to be temporary and disappeared by the correction of electrode placement and changing stimulation parameters (3).

\subsection{Classification of Seizures and Epilepsies}

The term epilepsy includes a number of different syndromes characterized predominantly by recurrent unprovoked seizures and can be symptomatic (with known etiology) or idiopathic (with no clear etiology other than a possible genetic predisposition) $(4,5)$. Epileptic seizures are characterized as abnormal hyperexcitable, hypersynchronous neuronal activity and their clinical manifestation depends on the place of seizure onset and subsequent spread (6). In general, epilepsy syndromes can be classified into two broad categories: generalized and partial syndromes $(7,8)$. In generalized epilepsies, seizure activity begins simultaneously over both brain hemispheres and can occur as one of several types; myoclonic, generalized tonic-clonic, absence or atypical absence. Most of these types of epilepsies have a genetic origin and in many cases neurologic function is normal. Absence seizures in which occur brief and sudden loss of consciousness are the most pure type of generalized epilepsy and characterized by bilaterally synchronized spike-and-wave discharges in the electroencephalogram (EEG) over wide cortical areas (9). In partial epilepsies, by contrast, seizures originate only from one brain hemisphere (most commonly from the temporal lobe) and may result from a traumatic brain injury (10) or may have a genetic origin (11). Among partial epilepsy, temporal lobe complex partial epilepsy is the most common type of acquired epilepsy in adult and characterized by recurrent epileptic seizures (12).

\subsection{Thalamus and Its Role in Epilepsy}

The thalamus is a small structure within the brain situated just above the brain stem between the cerebral cortex and the midbrain. It has reciprocal connections with cerebral cortex and limbic system $(13,14)$. These connections play a role in relaying sensory and motor information as well as regulation of sleep, alertness and wakefulness in the normal physiological state. In general, the thalamus is divided into two subdivisions: dorsal thalamus and ventral thalamus. The dorsal thalamus contains a number of anatomically and functionally distinct nuclei that are associated with an individual sensory, motor or limbic function. These nuclei receive input from the sensory organs and then transmit it to the functionally corresponding primary sensory cortical areas, from which, in turn, they receive modulatory projections. The thalamus includes also another area that is anatomically and functionally different from the dorsal thalamus (15) and known as the ventral thalamus. Unlike dorsal thalamus, the ventral thalamus does not project to cortex, but it instead targets the dorsal thalamus. The most eminent part of the ventral thalamus is the thalamic reticular nucleus (TRN), which is a relatively thin sheet of thalamus that exclusively contains GABAergic neurons enclosed in the dorsal thalamus $(16,17)$. The reticular thalamic nucleus is considered to be a generator of various wave rhythms, due to having an intrinsic ability to generate rhythmic oscillatory activity, which can transform into Spike-and-wave discharges. Spike-and-wave discharges are regarded to be a hallmark of idiopathic generalized epilepsy. Moreover, recently an important role of nucleus anterior thalami has been shown in bilateral Spike-and-wave discharges synchrony (18-20). However, the role of thalamus in partial epilepsy has been poorly understood. There are evidences showing the involvement of thalamus in patients with temporal lobe epilepsy (21). For example, Bertram et al. reported that in animal models of temporal Lobe complex partial epilepsy, there is a significant neuronal loss with synaptic changes in the midline thalamic regions, which can enhance the excitability of the thalamolimbic circuits (22). In addition, increased GABA activity in medial dorsal nucleus and medline region of the thalamus reduced seizure duration significantly $(22,23)$. Furthermore, inactivation of thalamus by tetrodotoxin (TTX) suppressed pilocarpine-induced seizures (24). It is about six decades that the role of thalamic nuclei in the generation of idiopathic generalized seizures has been recognized. Idiopathic generalized epilepsies are characterized by generalized spike and wave discharges in EEG. Involvement of thalamus and its cortical interactions are considered essential in the generation of spike-and-wave discharges. For example, some studies have shown the role of posterolateral and midline thalamic nuclei in the generation of generalized seizures in animal models of absence seizures (25, 26) and in humans with depth electrode recordings (27). In this line, involvement of anterior, centromedian and parafascicular thalamic nuclei during generalized spike-and-wave discharges (28) as well as that of anterior and mediodorsal nuclei of the thalamus in animal models of epilepsy induced by pentylenetetrazol (PTZ) or bicuculline (29) have been demonstrated. Moreover, unilateral thalamic lesions have been revealed in magnetic resonance imaging of two patients with IGE (idiopathic generalized epilepsy) (30). These findings suggest that several nuclei of thalamus have a role in neuronal circuits of seizures. 


\subsection{Electrical Stimulation of Anterior and Centro- median Thalamic Nuclei in Animal and Human Studies for the Treatment of Epilepsy}

In patients with epilepsy, DBS in anterior nucleus of the thalamus (ANT), centromedian nucleus of the thalamus (CMN), caudate nucleus, cerebellum, hippocampus, hippocampal commissure, amygdala, subthalamic nucleus, mammillary bodies, corpus callosum and neocortex has been evaluated for treatment of intractable epilepsy. Here, we reviewed DBS application in ANT and CMN in animal models and patients with epilepsy, since a large body of DBS studies have been conducted on thalamic nuclei, particularly ANT. Thalamic nuclei DBS outcomes in animal epilepsy models and patients with epilepsy have been summarized in Tables 1 and 2 .

\subsubsection{Animal Studies}

Potential usefulness of DBS application for the treatment of epilepsy has been tested in animal models of epilepsy induced by pentylenetetrazol, kainic acid, bicuculline, picrotoxin or using electrical kindling (31-37). Lado FA discovered that bilateral stimulation of the ANT with low frequency $(8 \mathrm{~Hz})$ increased seizures frequency (38). Hamani and coworkers reported that bilateral high-frequency stimulation of ANT delayed the onset of pilocarpine-induced status epilepticus (SE), but it failed to prevent SE (in 56\% of the animals), while bilateral lesions of ANT prevent SE development in all animals after pilocarpine injection. In this study, animals experienced unilateral or bilateral electrical stimulation of ANT or unilateral or bilateral ANT lesioning. The control group received bilateral placement of electrodes in ANT, but no stimulation (39). Unilateral stimulation or lesioning in these animals did not reduce the occurrence of seizure significantly. They concluded that bilateral stimulation of anterior thalamic nucleus and thalamotomies are protective against pilocarpine-induced SE. In a study, left ANT stimulation with high frequency of $200 \mathrm{~Hz}$ and low intensity current of $50 \mu \mathrm{A}$, beginning from $1 \mathrm{~h}$ before the pilocarpine administration for seizure induction significantly reduced the occurrence rate of seizure activity in rats, while right ANT stimulation had little effect on the occurrence rate of seizures (40).

\subsubsection{Human Studies}

Osorio and colleagues conducted bilateral DBS of ANT (175 Hz, 4.1 V, pulse width of $90 \mu \mathrm{s}$ ) for four patients with mesial temporal lobe complex partial epilepsy. The stimulation was conducted as intermittent with 1 minute on and 5 minutes off. Results indicated a mean $75.6 \%$ reduction in seizure frequency in all patients (41). In a study, bilateral DBS (130 Hz, 3-7 V, $90 \mu \mathrm{s})$ was performed for six patients with intractable epilepsy. Electrodes were implanted for three patients in ANT and for three patients in subthalamic nucleus. The patients with DBS of ANT showed a $75.4 \%$ reduction in seizure frequency, while in those with DBS of subthalamic nucleus seizure frequency reduced by $49.1 \%$ (42). Lim et al. conducted bilateral stimulation of ANT in four patients (one patient with generalized seizures and three patients with partial seizures). Stimulus parameters were 4-5 V, $90-110 \mathrm{~Hz}$ and $60-90 \mu \mathrm{s}$. Results showed a $49 \%$ reduction in seizure to ANT stimulation. In addition, a $67 \%$ reduction in seizure frequency was observed only with bilateral inserting electrodes in ANT (43). In another study, bilateral neurostimulation of $\operatorname{ANT}(100 \mathrm{~Hz}, 10 \mathrm{~V}$, and 90-msec) in five patients with medically refractory epilepsy resulted in a mean 54\% decrease in seizure frequency. Two patients showed a seizure reduction of $\geq 75 \%$. In this study stimulation was in an intermittent pattern with 1 minute on and 5 minutes off (44). Kerrigan et al. conducted bilateral DBS of ANT (with the frequency of $100 \mathrm{~Hz}$, pulse width of $90 \mu \mathrm{s}$ and the intensity of 1-10 V) for five patients with intractable partial seizures. The voltage was incrementally increased during 12 30 weeks, depending on the clinical response of patients. Results indicated that DBS significantly reduced seizure frequency in one patient and reduction in frequency of seizures in four patients was less than $50 \%$, although it was not significant (45). In a study, long-term follow-up of

Table 1. Deep Brain Stimulation Outcomes in Animal Models of Epilepsy ${ }^{\text {a }}$

\begin{tabular}{|c|c|c|c|c|c|}
\hline Author & Year & Target & Animal Model of Epilepsy & Stimulation Parameters & Main Findings \\
\hline Lado et al. & 2003 & ANT & Electrical kindling & $8 \mathrm{~Hz}$, bilateral stimulation & $\begin{array}{l}\text { Increase in seizures fre- } \\
\text { quency }\end{array}$ \\
\hline Hamani et al. & 2004 & ANT & $\begin{array}{c}\text { Pilocarpine model of epi- } \\
\text { lepsy }\end{array}$ & $\begin{array}{c}\text { bilateral high-frequency stimu- } \\
\text { lation }\end{array}$ & Delay in the onset of SE \\
\hline Hamani et al. & 2004 & ANT & $\begin{array}{c}\text { Pilocarpine model of epi- } \\
\text { lepsy }\end{array}$ & Unilateral stimulation & $\begin{array}{c}\text { A nonsignificant reductior } \\
\text { in seizure frequency }\end{array}$ \\
\hline Jou et al. & 2013 & left ANT & $\begin{array}{l}\text { Pilocarpine model of epi- } \\
\text { lepsy }\end{array}$ & $\begin{array}{l}\text { Unilateral high frequency } \\
\text { stimulation of } 200 \mathrm{~Hz} \text { and low } \\
\text { intensity current of } 50 \mu \mathrm{A}\end{array}$ & $\begin{array}{c}\text { A significant reduction in } \\
\text { seizure frequency }\end{array}$ \\
\hline
\end{tabular}

a ANT, Anterior nucleus of thalamus. 
Mehranfard $N$ et al.

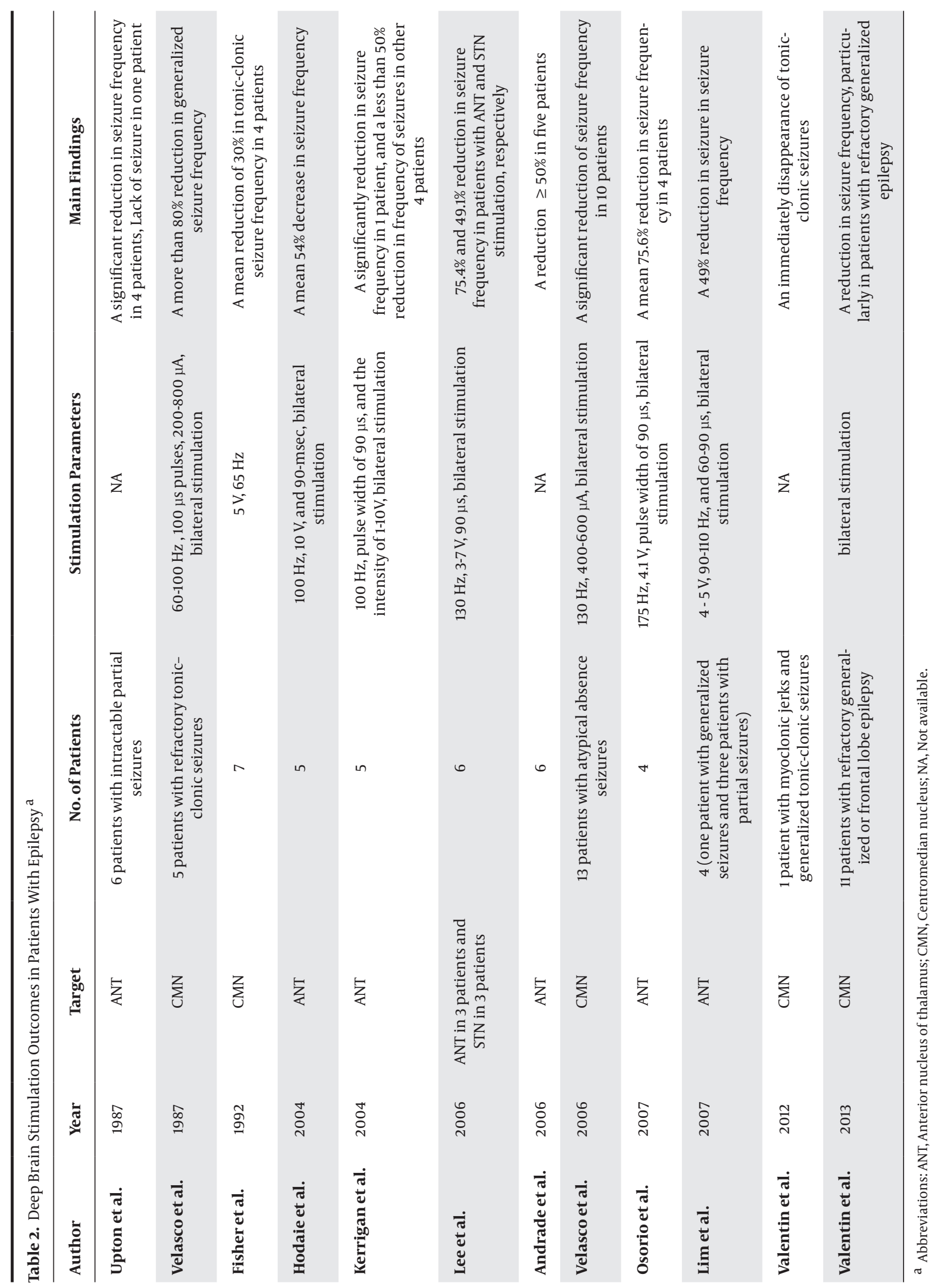


six patients with epilepsy with ANT DBS showed a reduction $\geq 50 \%$ in five patients. In these patients, electrode implantation in ANT was followed by seizure reduction 1 to 3 months before stimulation and authors suggested the possibility of a beneficial microthalamotomy effect (46). In another study, Upton et al. evaluated the effect of electrical stimulation of ANT in six patients with medically intractable partial seizures. Results indicated a statistically significant reduction in seizure frequency in four patients. One patient was shown to be seizure-free for the last two years. Measurement of regional cerebral glucose metabolism, blood cortisol levels and blood levels of valproic acid, diphenylhydantoin and carbamazepine in two patients showed a marked change in these factors during periods of stimulation compared to periods without stimulation (47).

Neurostimulation of centromedian-thalamic nucleus for treatment of refractory epilepsy has been performed in several studies. Centromedian thalamic nucleus is the part of the reticulothalamocortical system involved in cerebral cortex excitability (48). In 1987, bilateral DBS CMN was conducted in five patients with refractory tonic-clonic seizures. Stimulation $(60-100 \mathrm{~Hz}, 100 \mu \mathrm{s}$ pulses, $200-800 \mu \mathrm{A}$ ) was delivered for 2 hours daily, in a pattern of 1 minute on and 4 minutes off. Results showed more than $80 \%$ reduction in generalized seizure frequency (49). In a study, bilateral centromedian thalamic nucleus DBS in 11 patients with refractory generalized or frontal lobe epilepsy improved seizure frequency, particularly in patients with refractory generalized epilepsy (50). In another study, electrical stimulation of CMN was effective in patients with generalized tonic-clonic seizures and atypical absences (51). Furthermore, electrical stimulation of CMN in 49 patients with generalized, frontal and temporal lobe epileptic seizures was highly efficient to control patients with generalized tonic-clonic seizures, atypical absences and tonic seizures, but not in those with partial seizures. Stimulation protocol was 1 minute on and 4 minutes off for 24 hours, at $60-130 \mathrm{~Hz}, 2.5-5.0 \mathrm{~V}$, 210-450 $\mu \mathrm{s}$ (51). Bilateral stimulation of the parvocellular division of the CMN $(130 \mathrm{~Hz}, 400-600 \mu \mathrm{A})$ in 13 patients with atypical absence seizures of the Lennox-Gastaut syndrome, which is characterized by frequent medically intractable seizures, reduced seizure frequency significantly in 10 patients (52). A placebo-controlled study of centromedian thalamic stimulation in seven patients with intractable epilepsy with an intermittent protocol of 1 minute on $(5 \mathrm{~V}, 65 \mathrm{~Hz})$ and 4 minutes off stimulation caused a mean reduction of $30 \%$ in tonic-clonic seizure frequency in four patients compared to baseline when stimulator was on and a decrease of $8 \%$ when the stimulator was off, but these differences were not statistically significant (53). Moreover, bilateral DBS of the CMN in a patient with myoclonic jerks and generalized tonic-clonic seizures immediately was associated with disappearance of tonic-clonic seizures and generalized periodic epileptiform discharges (54).

\section{Results}

Neurostimulation of ANT and CMN particularly is effective in improvement of partial and generalized tonicclonic seizures, respectively. However, the efficiency of thalamic stimulation in treating refractory epilepsy depends on the stimulation parameters, particularly frequency. For example, low frequency stimulation of ANT was epileptogenic, while high frequency stimulation reduced seizure frequency both in experimental and clinical studies. Moreover, most studies of thalamic nuclei DBS demonstrated antiepileptic feature by application of a high-intensity current (320 - $800 \mu \mathrm{A})$ or a high-voltage (4 -10 V). However, electrical stimulation of ANT with high-intensity or high voltage currents might affect the memory, since anterior nucleus of thalamus is a significant nucleus in the Papez circuit involved in memory. This hypothesis is supported by a study in which Hamani et al. demonstrated that ANT stimulation at relatively high current of $500 \mu \mathrm{A}$ disrupted the acquisition of contextual fear conditioning and impaired performance on a spatial alternating task in rats (55). There is an animal study indicating the efficacy of unilateral stimulation of ANT with low intensity current to control the occurrence of seizure in pilocarpine-induced seizure. In this study, left ANT DBS was applied 1 hour or 30 minutes before seizure induction (40). Difference in timing ANT DBS within the same anatomic target makes it difficult to compare the results of this study to other studies, suggesting the application of ANT DBS after induction of seizure. One the other hand, in contrast to DBS human studies performed in patients with chronic epilepsy, most DBS experimental studies are conducted before starting spontaneous recurrent seizures that might be due to differences resulted from animal and human studies, suggesting DBS application in experimental studies after the animals acquired epilepsy. Results showed that stimulation paradigm of the unilateral or bilateral thalamic nuclei DBS has an impact on the effects of stimulation to prevent seizures. Stimulation protocol in most thalamic nuclei DBS was intermittent and there are reports suggesting that an intermittent stimulation paradigm might be more effective than a continuous paradigm (56). DBS program in CMN in most studies was in an intermittent pattern and associated with a reduction of generalized seizure. DBS in ANT, although, in several studies was in an intermittent model, implantation of DBS electrodes without stimulation in ANT and lesioning of ANT in a few reports appeared to be effective in reduction of seizure frequency and hence, stimulation pattern in ANT DBS for seizure treatment might have no significant effect on the effectiveness of procedure.

\subsection{Possible Mechanisms of Thalamic Nuclei DBS in Treatment of Epilepsy}

It is well known that certain subtypes of epileptic seizures are associated with oscillatory activity in the thalamus (57) and deep brain stimulation of specific thalamic nuclei has 
been indicated able to abolish or reduce spindles oscillations in thalamus. Although, the precise mechanism by which DBS is able to eliminate seizures associated with epilepsy remains largely unknown, there are evidences showing that high frequency stimulation of the thalamus leads to neurotransmitter release $(58,59)$. Indeed, it has been demonstrated that high-frequency stimulation of thalamus increased extracellular adenosine significantly (60). In addition, in a study, Lee and coworkers reported that high-frequency stimulation generates excitatory postsynaptic potentials and the antagonists of glutamate receptor can eliminate the excitatory postsynaptic potentials caused by high frequency stimulation in vitro (61), supporting the hypothesis that glutamate release is involved in high frequency stimulation function. A few years later, Tawfik et al. showed that high-frequency stimulation increased extracellular glutamate and adenosine levels in the thalamic slices and demonstrated that glutamate and adenosine release in slices was able to abolish spontaneous spindle oscillations. In this study, glutamate release was not inhibited by blocking the release of neurotransmitter from neurons. However, authors showed that high frequency stimulation of isolated astrocytes resulted in glutamate release, suggesting the role of astrocytic release in elevating extracellular glutamate levels (62). These findings present evidence consistent with a role of glutamate and adenosine in the modulation of neuronal responses that are essential for the cessation of abnormal spindles oscillations in thalamus. Further studies aimed deep brain stimulation of astrocytes in addition to thalamic neurons might be useful in the treatment of certain subtypes of epileptic seizures.

\section{Conclusions}

Encouraging results of neurostimulation of ANT in the treatment of refractory epilepsy, particularly in patients with partial epilepsy, make it the most well-established target for the treatment of this type of epilepsy. Although electrical stimulation of CMN is associated with an improvement in generalized tonic clonic seizures, further studies are needed to determine the effectiveness of CMN DBS in this type of seizure. Although lesions or resection of ANT in several studies has been shown to be effective in reducing epileptic seizures, ANT DBS in contrast to surgical resection has the advantages of flexibility and reversibility able to protect against epileptic seizures. Further studies are needed to determine the risk/benefit ratio of thalamic nuclei stimulation in the treatment of limbic and generalized seizures and to recognize the long-term effects of neurostimulation on epileptic brain network and memory, since anterior nucleus of thalamus has a significant role in memory and cognitive function.

\section{Acknowledgements}

This work was supported by the electrophysiology research center, Neuroscience Institute, Tehran University of Medical Sciences.

\section{References}

1. Hauser WA, Annegers JF, Kurland LT. Incidence of Epilepsy and Unprovoked Seizures in Rochester, Minnesota: 1935-1984. Epilepsia. 1993;34(3):453-8.

2. Kwan P, Arzimanoglou A, Berg AT, Brodie MJ, Allen Hauser W, Mathern G, et al. Definition of drug resistant epilepsy: consensus proposal by the ad hoc Task Force of the ILAE Commission on Therapeutic Strategies. Epilepsia. 2010;51(6):1069-77.

3. Burn DJ, Troster AI. Neuropsychiatric complications of medical and surgical therapies for Parkinson's disease. J Geriatr Psychiatry Neurol. 2004;17(3):172-80.

4. Blumenfeld H. From molecules to networks: cortical/subcortical interactions in the pathophysiology of idiopathic generalized epilepsy. Epilepsia. 2003;44 Suppl 2:7-15.

5. Mulley JC, Scheffer IE, Petrou S, Berkovic SF. Channelopathies as a genetic cause of epilepsy. Curr Opin Neurol. 2003;16(2):171-6.

6. Engel J, Pedley TA. Epilepsy: A Comprehensive Textbook.: LippincottRaven; 1998.

7. Proposal for Revised Classification of Epilepsies and Epileptic Syndromes. Epilepsia. 1989;30(4):389-99.

8. Benbadis SR. Epileptic seizures and syndromes. Neurol Clin. 2001;19(2):251-70.

9. Panayiotopoulos CP. Absences epilepsies. In: Engel J, Pedley TA editors. Epilepsy: A Comprehensive Textbook: Lippincott-Raven; 1998. pp. 2327-46.

10. Herman ST. Epilepsy after brain insult: Targeting epileptogenesis. Neurol. 2002;59(Issue 9, Supplement 5):S21-6.

11. Vadlamudi L, Scheffer IE, Berkovic SF. Genetics of temporal lobe epilepsy. J Neurol Neurosurg Psychiatry. 2003;74(10):1359-61.

12. Chang BS, Lowenstein DH. Epilepsy. $N$ Engl $J$ Med. 2003;349(13):1257-66.

13. Cavdar S, Onat FY, Cakmak YO, Yananli HR, Gulcebi M, Aker R. The pathways connecting the hippocampal formation, the thalamic reuniens nucleus and the thalamic reticular nucleus in the rat. $J$ Anat. 2008;212(3):249-56.

14. Van der Werf YD, Witter MP, Groenewegen HJ. The intralaminar and midline nuclei of the thalamus. Anatomical and functional evidence for participation in processes of arousal and awareness. Brain Res Rev. 2002;39(2-3):107-40.

15. Sherman SM, Guillery RW. Exploring the Thalamus.: Elsevier Science; 2001.

16. de Biasi S, Frassoni C, Spreafico R. GABA immunoreactivity in the thalamic reticular nucleus of the rat. A light and electron microscopical study. Brain Res.1986;399(1):143-7.

17. Houser CR, Vaughn JE, Barber RP, Roberts E. GABA neurons are the major cell type of the nucleus reticularis thalami. Brain Res. 1980;200(2):341-54.

18. Mirski MA, Ferrendelli JA. Anterior thalamic mediation of generalized pentylenetetrazol seizures. Brain Res.1986;399(2):212-23.

19. Bokor H, Frere SG, Eyre MD, Slezia A, Ulbert I, Luthi A, et al. Selective GABAergic control of higher-order thalamic relays. Neuron. 2005;45(6):929-40.

20. Bartho P, Freund TF, Acsady L. Selective GABAergic innervation of thalamic nuclei from zona incerta. Eur J Neurosci. 2002;16(6):999-1014.

21. Guye M, Regis J, Tamura M, Wendling F, McGonigal A, Chauvel P, et al. The role of corticothalamic coupling in human temporal lobe epilepsy. Brain. 2006;129(Pt 7):1917-28.

22. Bertram EH, Mangan PS, Zhang D, Scott CA, Williamson JM. The midline thalamus: alterations and a potential role in limbic epilepsy. Epilepsia. 2001;42(8):967-78.

23. Bertram EH, Zhang D, Williamson JM. Multiple roles of midline dorsal thalamic nuclei in induction and spread of limbic seizures. Epilepsia. 2008;49(2):256-68.

24. Li Y-H, Li J-J, Lu Q-C, Gong H-Q, Liang P-J, Zhang P-M. Involvement of Thalamus in Initiation of Epileptic Seizures Induced by Pilocarpine in Mice. Neural Plast. 2014;2014.

25. Gloor P, Fariello RG. Generalized epilepsy: some of its cellular mechanisms differ from those of focal epilepsy. Trends Neurosci. 1988;11(2):63-8. 
26. Vergnes M, Marescaux C, Depaulis A, Micheletti G, Warter JM. Spontaneous spike and wave discharges in thalamus and cortex in a rat model of genetic petit mal-like seizures. Exp Neurol. 1987;96(1):127-36.

27. Niedermeyer E, Laws ER, Walker AE. Depth EEG Findings in Epileptics With Generalized Spike-Wave Complexes. Arch Neurol. 1969;21(1):51-8.

28. Tyvaert L, Chassagnon S, Sadikot A, LeVan P, Dubeau F, Gotman J. Thalamic nuclei activity in idiopathic generalized epilepsy: an EEG-fMRI study. Neurology. 2009;73(23):2018-22.

29. Miller JW, Ferrendelli JA. The central medial nucleus: thalamic site of seizure regulation. Brain Res.1990;508(2):297-300.

30. Nguyen DK, Podubnaia AB, Carmant L, Guilbert F, Cossette P. Generalized epilepsy and classic spike-wave discharges with unilateral thalamic lesions. Arch Neurol. 2006;63(9):1321-3.

31. Jensen AL, Durand DM. Suppression of axonal conduction by sinusoidal stimulation in rat hippocampus in vitro. J Neural Eng. 2007;4(2):1-16.

32. Lian J, Bikson M, Sciortino C, Stacey WC, Durand DM. Local suppression of epileptiform activity by electrical stimulation in rat hippocampus in vitro. J Physiol. 2003;547(Pt 2):427-34.

33. Mirski MA, McKeon AC, Ferrendelli JA. Anterior thalamus and substantia nigra: two distinct structures mediating experimental generalized seizures. Brain Res.1986;397(2):377-80.

34. Nishida N, Huang ZL, Mikuni N, Miura Y, Urade Y, Hashimoto N. Deep brain stimulation of the posterior hypothalamus activates the histaminergic system to exert antiepileptic effect in rat pentylenetetrazol model. Exp Neurol. 2007;205(1):132-44.

35. Shi LH, Luo F, Woodward D, Chang JY. Deep brain stimulation of the substantia nigra pars reticulata exerts long lasting suppression of amygdala-kindled seizures. Brain Res. 2006;1090(1):202-7.

36. Usui N, Maesawa S, Kajita Y, Endo O, Takebayashi S, Yoshida J. Suppression of secondary generalization of limbic seizures by stimulation of subthalamic nucleus in rats. J Neurosurg. 2005;102(6):1122-9.

37. Ziai WC, Sherman DL, Bhardwaj A, Zhang N, Keyl PM, Mirski MA. Target-specific catecholamine elevation induced by anticonvulsant thalamic deep brain stimulation. Epilepsia. 2005;46(6):878-88.

38. Lado FA, Velíšek L, Moshé SL. The Effect of Electrical Stimulation of the Subthalamic Nucleus on Seizures Is FrequencyDependent. Epilepsia. 2003;44(2):157-64.

39. Hamani C, Ewerton FIS, Bonilha SM, Ballester G, Mello LEAM, Lozano AM. Bilateral Anterior Thalamic Nucleus Lesions and High-frequency Stimulation Are Protective against Pilocarpine-induced Seizures and Status Epilepticus. Neurosurg. 2004;54(1):191-7.

40. Jou SB, Kao IF, Yi PL, Chang FC. Electrical stimulation of left anterior thalamic nucleus with high-frequency and low-intensity currents reduces the rate of pilocarpine-induced epilepsy in rats. Seizure. 2013;22(3):221-9.

41. Osorio I, Overman J, Giftakis J, Wilkinson SB. High frequency thalamic stimulation for inoperable mesial temporal epilepsy. Epilepsia. 2007;48(8):1561-71.

42. Lee KJ, Jang KS, Shon YM. Chronic deep brain stimulation of subthalamic and anterior thalamic nuclei for controlling refractory partial epilepsy. Acta Neurochir Suppl. 2006;99:87-91.

43. Lim SN, Lee ST, Tsai YT, Chen IA, Tu PH, Chen JL, et al. Electrical stimulation of the anterior nucleus of the thalamus for intractable epilepsy: a long-term follow-up study. Epilepsia. 2007;48(2):342-7.

44. Hodaie M, Wennberg RA, Dostrovsky JO, Lozano AM. Chronic Anterior Thalamus Stimulation for IntractableEpilepsy. Epilepsia. 2002;43(6):603-8.

45. Kerrigan JF, Litt B, Fisher RS, Cranstoun S, French JA, Blum
$\mathrm{DE}$, et al. Electrical stimulation of the anterior nucleus of the thalamus for the treatment of intractable epilepsy. Epilepsia. 2004;45(4):346-54.

46. Andrade DM, Zumsteg D, Hamani C, Hodaie M, Sarkissian S, Lozano AM, et al. Long-term follow-up of patients with thalamic deep brain stimulation for epilepsy. Neurology. 2006;66(10):1571-3.

47. Upton ARM, Amin I, Garnett S, Springman M, Nahmias C, Cooper IS. Evoked Metabolic Responses in the LimbicStriate System Produced by Stimulation of Anterior Thalamic Nucleus in Man. Pacing Clin Electrophysiology. 1987;10(1):217-25.

48. Jasper HH. Current evaluation of the concepts of centrecephalic and cortico-reticular seizures. Electroencephalography Clin Neurophysiol. 1991;78(1):2-11.

49. Velasco F, Velasco M, Ogarrio C, Fanghanel G. Electrical stimulation of the centromedian thalamic nucleus in the treatment of convulsive seizures: a preliminary report. Epilepsia. 1987;28(4):421-30.

50. Valentin A, Garcia Navarrete E, Chelvarajah R, Torres C, Navas M, Vico L, et al. Deep brain stimulation of the centromedian thalamic nucleus for the treatment of generalized and frontal epilepsies. Epilepsia. 2013;54(10):1823-33.

51. Velasco F, Velasco M, Jimenez F, Velasco AL, Marquez I. Stimulation of the Central Median Thalamic Nucleus for Epilepsy. Stereotactic Functional Neurosurg. 2001;77(1-4):228-32.

52. Velasco AL, Velasco F, Jimenez F, Velasco M, Castro G, Carrillo-Ruiz JD, et al. Neuromodulation of the centromedian thalamic nuclei in the treatment of generalized seizures and the improvement of the quality of life in patients with Lennox-Gastaut syndrome. Epilepsia. 2006;47(7):1203-12.

53. Fisher RS, Uematsu S, Krauss GL, Cysyk BJ, McPherson R, Lesser $\mathrm{RP}$, et al. Placebo-controlled pilot study of centromedian thalamic stimulation in treatment of intractable seizures. Epilepsia. 1992;33(5):841-51.

54. Valentin A, Nguyen HQ, Skupenova AM, Agirre-Arrizubieta Z, Jewell S, Mullatti N, et al. Centromedian thalamic nuclei deep brain stimulation in refractory status epilepticus. Brain Stimul. 2012;5(4):594-8.

55. Hamani C, Dubiela FP, Soares JC, Shin D, Bittencourt S, Covolan L, et al. Anterior thalamus deep brain stimulation at high current impairs memory in rats. Exp Neurol. 2010;225(1):154-62.

56. Vercueil L, Benazzouz A, Deransart C, Bressand K, Marescaux C Depaulis A, et al. High-frequency stimulation of the sub-thalamic nucleus suppresses absence seizures in the rat: comparison with neurotoxic lesions. Epilepsy Res.1998;31(1):39-46.

57. McCormick DA, Contreras D. On the cellular and network bases of epileptic seizures. Annu Rev Physiol. 2001;63:815-46.

58. Lee KH, Hitti FL, Shalinsky MH, Kim U, Leiter JC, Roberts DW. Abolition of spindle oscillations and $3-\mathrm{Hz}$ absence seizurelike activity in the thalamus by using high-frequency stimulation: potential mechanism of action. J Neurosurg. 2005;103(3):538-45.

59. Anderson T, Hu B, Pittman Q, Kiss ZH. Mechanisms of deep brain stimulation: an intracellular study in rat thalamus. $J$ Physiol. 2004;559(Pt 1):301-13.

60. Bekar L, Libionka W, Tian GF, Xu Q, Torres A, Wang X, et al. Adenosine is crucial for deep brain stimulation-mediated attenuation of tremor. Nat Med. 2008;14(1):75-80.

61. Lee KH, Chang SY, Roberts DW, Kim U. Neurotransmitter release from high-frequency stimulation of the subthalamic nucleus. $J$ Neurosurg. 2004;101(3):511-7.

62. Tawfik VL, Chang SY, Hitti FL, Roberts DW, Leiter JC, Jovanovic S et al. Deep brain stimulation results in local glutamate and adenosine release: investigation into the role of astrocytes. Neurosurgery. 2010;67(2):367-75. 